THURSDAY, JULY 26,1883

\section{ZOOLOGY AT THE FISHERIES EXHIBITION}

I.

THE manifold relations of zoological science to the various fish industries are, on the whole, fairly well illustrated in the Kensington Exhibition if we take together into consideration all the exhibits of foreign countries, of these islands, and of British colonies. Considered alone, however, the British department is remarkable for the extreme paucity and insignificance of exhibits having any scientific value. This is due to the fact that no attempt was made by those who organised the exhibition to obtain scientific advice and direction, so as to enable them to make application to the individuals or museums possessing objects illustrating the scientific aspects of fish and fisheries, and that no individual with authority and responsibility has attempted to bring together that class of objects - which are abundant enough in both private and public collections in England, and form, on the contrary, a large portion of the exhibits of foreign countries. Thus under the direction of a properly-trained zoologist-Prof. Spencer Baird-the Smithsonian Institute has been able to form a collection which is sent over to this country by the American Government as the official representative collection. It is not an exaggeration to say that this collection, both on account of the range and variety of its objects and the instructive way in which they have been disposed and treated by the American Commissioner, Mr. Brown Goode, has been the admiration of all visitors. Similarly the Swedish authorities have intrusted Prof. Smidt with the duty of bringing together objects illustrating the zoological aspect of fish and fisheries in Sweden. Collections from the museums of Gothenburg and Stockholm and from eminent Swedish zoologists are consequently exhibited in the Swedish department. So also in the case of the Netherlands, of British India, and of New South Wales, we find the well-known naturalists, Prof. Hubrecht, Dr. Francis Day, and Mr. Ramsay, specially charged with such responsibility.

There can be no doubt that the collections, both public and private, of this country, might have been brought into requisition and made to furnish such an exhibition of marine and freshwater fishes, of their food, of their parasites, and other enemies, and again of the like objects in relation to oysters (both edible and pearl-bearing), lobsters, sponges, and precious coral, as no other country could possibly bring together.

The exhibits of zoological specimens may be classed under three heads, viz. (I) those which are strictly zoological, that is to say, intended to illustrate either the aquatic inhabitants of a particular district, or the structure and life history of a particular species; (2) those of economic significance, illustrating the cultivation or modes of occurrence of an aquatic organism or organisms having a direct commercial importance; (3) those having an ornamental or personal value, and being of the nature of trophies, such, for instance, as Lady Brassey's case of corals, and the many cases of VOL. XXVIII.-No. 7I7 dried stuffed skins of large trout and pike exhibited by angling societies.

The most important collection of the first group is one comprising representatives of all classes of marine animals preserved in alcohol, and numbering nearly 400 specimens. It is sent by Dr. Anton Dohrn, the director of the Zoological Station of Naples, and is not placed in the Italian court, but in the Eastern Arcade, since it is sent by a private individual, and not through the Italian Government. The remarkable feature about this collection is the extraordinary beauty of the specimens in respect of preservation. Every naturalist is aware of the difficulty of getting such creatures as polyps, jelly-fish, and Salpæ to retain when placed in a preserving fluid anything like a satisfactory semblance of their living form and colour. To improve the methods of preserving marine organisms for museums and the workshops of comparative anatomists has been for some years one of Dr. Dohrn's objects in the work of his "Station," and this collection shows how far he and his assistants have succeeded in devising methods. To appreciate Dr. Dohrn's success, we have only to pass to some of the other collectionsvery good in their way, and showing the best state of the bottling-art out of Naples-and by the inferiority of the condition of the specimens in the latter we learn Dr. Dohrn's merit. Sudden killing with saturated solution of corrosive sublimate and gradual transfer to strong alcohol is one general method used at Naples for retractile polyps and fragile worms; brief immersion in weak chromic acid before transfer to weak spirit is another method used for jelly-fish and mollusks; narcotising by aid of tobaccofumes another device. But the skilful application of such ingenious processes variously appropriate to this or that kind of animal can only be satisfactorily learnt in the Naples laboratory itself. Accordingly Dr. Dohrn has made arrangements for giving special instruction in this subject to naval officers and others, such persons being admitted for a fee paid by the Governments to which they belong, to a three months' course of instruction in the preservation of marine organisms for scientific purposes. Already, much to the credit of the naval departments of their respective Governments, both German and Italian officers and navy surgeons have been sent to receive such instruction at Naples, and a collection of coral-polyps and Siphonophora has been received from Monte Video, prepared by an Italian officer who had availed himself of the Naples course of instruction. This collection has been pronounced superior in condition and fitness for study to any collection from tropical waters hitherto brought to Europe. A second collection made by the same officer in Magellan Straits is on its way to Europe. There can be no doubt of the very great value of the new line of activity which Dr. Dohrn has traced for the Naples Station.

The Naples exhibit contains some interesting fish and a particularly fine series of Salpæ, of Mollusks, and of Anthozoa and Medusæ. It should not be allowed to return to Naples, and we believe is offered for sale. Dr. Dohrn also exhibits the publications, comprising many beautiful coloured plates, of the Naples Zoological Station. The series of volumes illustrating the "Fauna and Flora of the Gulf of Naples" should be in the library of every lover of natural history. 
Second to Dr. Dohrn's collection, but of value as a complete local collection of all classes of marine animals, is that from the Gothenburg Museum exhibited by Mr. Oscar Dickson. The most interesting specimens here are several series illustrating the development of Pleuronectid and other fishes.

A very interesting general collection is exhibited by the Government of New South Wales, in spite of some mishaps to bottles in the course of a long journey. The Sydney Museum promises to become one of the grandest zoological institutions in the world, the colonial Government having appreciated the unique interest attaching to the natural history of the Australian continent, and wisely having determined that what money can do to build up in Syaney the great illustrative collection dealing with that subject, shall be done. Though not exhibited as examples of preservation as are Dr. Dohrn's series, nor labelled and identified with neat accuracy as are $\mathrm{Mr}$. Dickson's, yet the Australian collection now at Kensington is of great interest to the professional zoologist, comprising many marine invertebrates as yet undetermined. It is under the charge of Mr. Ramsay, the accomplished curator of the Sydney Museum, who has brought over some of the reserve stores of the collection under his charge.

The American exhibit has the advantage of being the actual permanent collection of the National Museum of Washington, which has come into existence under the combined auspices of the United States Fisheries Commission and the Smithsonian Institute. The whole collection is not here, but we have a considerable part of it. For example, an admirable series of coloured casts of the fishes of the American waters, lifesize reproductions of the gigantic Octopus and Architeuthis, a complete series of the Crayfishes (Astacidæ) of North America and of the edible Crustacea generally, and samples of the more remarkable forms of life obtained in deep-sea exploration off the American coast.

In relation to the deep-sea specimens, we cannot but regret that no collection is shown in the Exhibition illustrating the results of the Challenger and other exploring expeditions conducted by the British Government. No such collection has, we believe, ever been presented to the inspection either of the general public or of professed zoologists, and the present would have been a very suitable occasion for sucb an exhibition. Whilst the Americans have taken the trouble to send across the Atlantic the newest dredging and sounding apparatus devised and employed by Agassiz, Sigsby, and others in their recent explorations of the deep-sea bottom, no such exhibit on the part of our own authorities is to be found.

In the Canadian department there is no general collection of any scientific importance, but amongst the zoological specimens, which (so far as the Invertebrates are concerned) are nearly all erroneously named, badly preserved, and unintelligently arranged, are some which are noteworthy. A bottle four feet high from British Columbia contains several specimens (nearly putrid) of the remarkable Pennatulid Osteocella, with flesh and polyps attached. Some ten years ago the calcified axes of these Alcyonarians excited considerable discussion in England, being mistaken by an eminent zoologist for the notochord of an unknown fish. In another bottle is a fine specimen (not labelled) of the very rare Cryptochiton Stelleri, whilst in one of the table-cases is a very large and probably new Hexactinellid sponge.

The collections from British India are remarkable, as comprising the important collection of Indian fishes belonging to Dr. Francis Day. The invertebrate collections are also extensive, but are not fully named.

As a general collection illustrating the British fauna of a certain size and important in relation to the food of fishes, should be mentioned the exhibition of living microscopic organisms by Mr. Thomas Bolton of Birmingham (in the Western Arcade). From day to day various living marine and freshwater Crustacea, Worms, Polyzoa, and Hydroids (also oyster-spat and newlyhatched fishes) are shown in small aquaria and under the microscope by this enterprising and meritorious naturalist. A complete collection of the drawings issued by $\mathrm{Mr}$. Bolton to the subscribers to his weekly "microscopic tubes" (concerning which our advertisement columns may be consulted) is also exhibited.

Special collections dealing with particular groups of animals are to be found scattered in the various foreign and British courts. A collection (preserved in alcohol) of freshwater Crustacea of remarkable completeness is exhibited by Dr. Lilljeborg in the Swedish Court. It comprises most of the species of Cladocera and Copepoda, which inhabit the great Scandinarian lakes and serve as food to fishes. Recently some remarkable species of Cladocera identical with these have been discovered by Mr. Conrad Beck in the lakes of Cumberland, and the collection now under notice has been purchased by two English naturalists to assist them in identifying the species present in the Scotch lakes, which they intend to explore immediately.

Aquatic insects and their larval forms have a special importance for fishes, since the larvæ often feed on young fish or fish-eggs, whilst the adult insects are preyed upon by the adult fish. In the Swedish department there are two interesting collections of such insects, and in the American department are two sample cases from the great collection of Prof. C. V. Riley, which exhibit in the most complete way both by actual specimens and adjacent illustrative diagrams the various phases of life of a few insects the larvæ of which inhabit the water. There is no serious attempt by any English exhibitor to deal with this subject.

In fact most of the English zoological exhibits come under our Classes 2 and 3 . There are most complete and valuable collections dealing with the growth of the oyster and the various conditions affecting it, as encountered by the oyster-culturist. The exhibit of Mr. Fell Woods is the most important of these. Mr. Henry Lee shows a very pretty series of oyster-shells and pearls in relation to their importance in the manufacture of ornaments, buttons, \&c. As trophies, we cannot pass without a word of admiration the gorgeous cases of corals, sponges, starfishes, and sea-mats exhibited by Miss Gardiner. They include finer specimens and a greater variety than either the trophy exhibited in Lady Brassey's name, or in the series from the Bahamas, which are well worth inspection. It is only proper that a protest should be entered here in the pages of a scientific journal, in referring to the 
Brassey collection. Some of the specimens appear to belong to a dealer, Mr. Bryce-Wright, and to these and others he has assigned names as though he were a serious zoologist. This travesty of science should not have been permitted. The names attached to the specimens are either incorrect applications of existing names or are gratuitous inventions (as for instance that of Brasseya radians), which can only mislead persons not specially acquainted with the history of corals.

Amongst the gigantic lobsters, clams, and stuffed fish there are some few s̀mall collections of scientific merit in the British exhibit. Dr. Francis Day shows a series of British fishes (alcohol specimens), Prof. McIntosh of St. Andrew's some coloured drawings of marine animals admirably executed by his sister, and a series of specimens of the salmon at various stages of development. Dr. Traquair of Edinburgh shows some exquisite drawings of fossil fishes, and H.R.H. the Duke of Edinburgh a collection of shells, scientifically named and arranged.

The parasites of fishes are not well represented in any part of the Exhibition. Dr. Spencer Cobbold shows a small collection of internal and external parasites, and a still smaller series (having, however, some special interest) is to be seen in the Russian court, where also the naturalist should not fail to study Dr. Grimm's important collection illustrating the fauna of the Caspian Sea. The most remarkable exhibit in the way of parasites is that of Dr. Antonio Valli of Trieste, who shows (in the Austrian Court) a collection of eighty-five specimens of Copepod Crustacea parasitic on the fishes of the Adriatic, accompanied by drawings and descriptions.

Curiously enough there is next to nothing in the Exhibition illustrating the diseases of fish. Some stuffed salmon with cotton-wool attached in patches to the head and fins do duty for the "Saprolegnia disease," and a not too accurate drawing of the Saprolegnia itself is exhibited in a part of the building which is about a quarter of a mile distant from the stuffed specimens. In a third locality is a cast of a salmon with cotton-wool also gummed on to represent "the disease," and near it an insufficiently stuffed skin of an old Kelt, which is offered as an example of the effects of "the arrow-beaded parasite."

In the space occupied by Chili, China, and the Straits Settlements some specimens of fishes, and of shell-fish, corals, \&c., are shown, which are not however scientifically named.

Finally, we would direct the reader's attention to two peculiarly interesting branches of fishery which are represented, though very poorly, in the present Exhibition. These are the sponge fishery and the coral fishery: the pearl fishery appears not to be represented at all. Collections of economic importance, showing the mode of diving for sponges in use in the Levant, and samples of Turkey sponges are shown in the Greek Court by Messrs. Marks and Son. By mistake (as seems probable) a specimen of Hyalonema, from another locality, has been placed in the case containing this fine collection of officinal sponges. From the Bahamas samples of commercial sponges are sent, and also (of very, similar quality) from Florida (in the American Court). The propagation of sponges by cutting is illustrated by two specimens in the American collec- tion, but no attempt is anywhere made to show the officinal sponge in its natural state, or to illustrate its lifehistory and distribution.

Similarly as commercial products we have the precious coral exhibited in the Italian Court by Signor Criscuolo. This exhibitor, however, also shows the method of dredging employed in the Gulf of Naples for obtaining the coral, and displays a number of the wooden crossbars with stone weights attached, and hempen tangles depending, which constitute the instrument used in this fishery. Specimens of other corals and shell-fish found in association with the red coral are also exhibited.

In no exhibit is there any attempt to illustrate the natural history of the precious coral, although its interest is no less than its value.

A strange illustration of the chance uses of sucb an exhibition as the present may be found in the Japanese department. Nothing could be worse or more unworthy than the Japanese exhibit. It consists of some sardines, a large crab (Macrocheira), three pieces of red coral, and some silks and lacquer work. The three pieces of coral are the first commercial examples of a new species of precious coral which will henceforward form an important article of trade for Japan. They have been purchased by Signor Criscuolo at a high price, and are said to be of the very finest quality. The new Japanese coral fisheries are destined to make the fortunes of those who first set them going, and will very possibly seriously injure, if they do not ruin the Neapolitan fishermen. Similar precious coral may in all probability be discovered by dredging operations on the shores of one or more of the numerous British colonies.

On a future occasion we shall publish some notes by Prof. Giglioli of Florence, on the whales, seals, birds, and fishes now to be seen at the Exhibition.

\section{PRECAUTIONS AGAINST CHOLERA}

HARLY in the month the Local Government Board L issued an Order to Port Sanitary Authorities conferring upon them special powers with a view of preventing the importation of cholera into this country. But cholera is a disease having many degrees of severity, and although "choleraic-diarrhœa" is to be regarded by the Port Authorities as synonymous with the fully developed affection, yet it is at times so mild that it may at any moment escape detection, and those suffering from it may make their way into our towns and villages. To meet such emergencies, and by way of aiding inland authorities and private individuals to rid their districts and their homes of the conditions favourable to the propagation of the cholera infection, a Memorandum on the Precautions against the Infection of Cholera has just been issued by Dr. Buchanan, F.R.S., the chief medical officer of the Local Government Board. The document, whilst expressing no opinion as to the channels of infection and the means of favouring the spread of the disease in other climates, declares with confidence that in England cholera is not infectious in the same degree and manner as are small-pox and scarlet fever, but that the matters which the patient discharges from his stomach and bowels contain the poison, and that their peculiar infectiveness is favoured by special local conditions which give the disease 